\title{
Conceptualização metafórica da anatomia em português: artérias, veias e nervos
}

\author{
Metaphorical conceptualization in \\ anatomy in the portuguese language: \\ arteries, veins and nerves
}

\section{Paula Fernanda Malaszkiewicz Sylvie Vandaele} Patrícia Chittoni Ramos Reuillard ${ }^{* * *}$

Resumo: A partir dos anos 1980, a metáfora passou a ser estudada do ponto de vista conceptual, sendo reconhecida na linguagem científica. Pode-se apreender a conceptualização metafórica de uma área especializada através da identificação dos índices de conceptualização metafórica. No campo da tradução, o conhecimento dos índices e do modo de conceptualização é fundamental, pois estão ligados à fraseologia do domínio. Este artigo tem como objetivo mostrar os resultados de uma pesquisa que buscou identificar e descrever os índices de conceptualização metafórica utilizados em Anatomia na descrição do posicionamento das artérias, das veias e dos nervos em língua portuguesa, continuando um estudo já realizado em língua inglesa e francesa. Após terem sido identificados, os índices foram distribuídos em categorias de representação fictícia e nos modos de conceptualização identificados.

Palavras-chave: Conceptualização metafórica; índices de conceptualização; fraseologia.

\footnotetext{
* Universidade Federal do Rio Grande do Sul

** Universidade de Montreal

*** Universidade Federal do Rio Grande do Sul
} 
MALASZKIEWICZ, P. F.; VANDAele, S.; ReuILlaRD, P. C. R.- Conceptualização metafórica da anatomia em português: artérias, veias e nervos

Abstract: Metaphor has been the focus of studies from a conceptual point of view since the 1980s. It is possible to describe the metaphorical conceptualizations that are prevalent in specialized areas through the identification of indices of metaphorical conceptualization. In the translation field, the knowledge of metaphorical conceptualization indices and modes is essential because they are linked to the phraseology of the domain. This article presents the results of a research that was aimed at identifying and describing the indices of metaphorical conceptualization used in anatomy in Portuguese, specifically for the positioning of the arteries, veins and nerves. This research has been inspired by a similar study previously conducted in the English and French languages. Indices of metaphorical conceptualization were identified and then classified into categories of fictive representations, thus allowing the characterization of various conceptualization modes.

Keywords: Metaphorical conceptualization; Indices of metaphorical conceptualization; Phraseology.

\section{Introdução}

Por muito tempo a metáfora foi considerada apenas como uma alegoria ao texto, sem valor cognitivo. Gradativamente, essa função apenas “decorativa” passou a ter seu papel questionado por autores como Richards (1936), Beardsley (1958) e Black (1962). Porém, a partir dos anos 1970, a metáfora se tornou objeto de interesse central das ciências humanas (SEARLE 1979; KitTAY 1987; ORTONY 1979; ORTONY et al. 1985, entre outros). Em 1979, Reddy publica o ensaio The conduit metaphor [metáfora do canal ${ }^{1}$ ], mostrando como se conceptualiza metaforicamente 0 conceito de comunicação. A partir do caminho aberto por Reddy, Lakoff \& Johnson (1980)

\footnotetext{
1 Também traduzido como "metáfora do conduto" por GARCEZ, MigliaVACCA et al (2000): Metáfora do conduto: um caso de conflito de enquadramento na nossa linguagem sobre a linguagem. In: Cadernos de Tradução, UFRGS, Porto Alegre, $n^{\circ}$ 9, pp. 5-47, jan-mar, 2000 [1979].
} 
MALASZKIEWICZ, P. F.; VANDAELE, S.; ReUILLARD, P. C. R.- Conceptualização metafórica da anatomia em português: artérias, veias e nervos

lançam a teoria da metáfora conceptual e afirmam que a metáfora está presente também na linguagem cotidiana, sendo muito mais que um simples ornamento linguístico: trata-se de um processo de pensamento por meio do qual uma representação mental é apreendida com o auxílio de outra representação já conhecida. Por exemplo, expressões metafóricas como "Seus argumentos são indefensáveis" ou "Jamais ganhei uma discussão com ele" são compreendidas a partir do uso do domínio da guerra, de onde são retiradas as informações para compreender o domínio discussão, resultando na metáfora conceptual DISCUSSÃO É GUERRA.

Além disso, estudos científicos (BOYD 1993; KUHN 1993; STENGERS \& SCHLANGer 1989; Temmerman 2000, entre outros, apud VANDAELE 2009) vêm comprovando que, ao contrário do que se apregoava, a metáfora não se restringe apenas à linguagem literária, sendo amplamente utilizada não só na linguagem cotidiana, como fora mostrado por Lakoff \& Johnson (1980), mas também na linguagem especializada.

A metáfora como parte da linguagem especializada já fora estudada anteriormente por diversos pesquisadores, tais como Temmerman (2000), Huang (2005), Oliveira (2011) e Faber (2012), mas principalmente sob o viés da Terminologia. Alguns autores a abordaram sob o viés da tradução, como Schaeffner (2004), no discurso político. No início dos anos 2000, Sylvie Vandaele começou a desenvolver seus trabalhos sobre conceptualização metafórica, ao estudar as metáforas conceptuais na biomedicina e sua relação com a tradução (VANDAELE 2000, 2002a, 2006; para uma síntese, ver VANDAELE 2009). Utilizando-se de corpora em francês, inglês e espanhol, a autora discutiu as relações entre modos de conceptualização, terminologia e fraseologia (por exemplo, VANDAELE 2000), não somente em textos especializados, mas também em textos publicitários (VANDAELE 2002b) e em textos de vulgarização (VANDAele \& RAFFo 2007). A autora observa que, na fraseologia, a conceptualização metafórica se realiza por meio da projeção de actantes prototípicos de predicados sobre os actantes expressos no discurso 
MALASZKIEWICZ, P. F.; VANDAele, S.; ReuILlaRD, P. C. R.- Conceptualização metafórica da anatomia em português: artérias, veias e nervos

na expressão metafórica (VANDAELE 2004). A partir dessa observação, ela desenvolveu um método de estudo inspirado na análise actancial da Teoria Sentido-Texto de Mel'Cuk (1995), possibilitando a anotação de corpora comparáveis em língua francesa e inglesa (VANDAELE \& BoudREAU 2006).

A noção de índice de conceptualização metafórica (doravante IC), que expressa o papel essencial do predicado em questão na expressão metafórica, que será retomada mais adiante, é proposta pela primeira vez em 2005 (VANDAELE \& LUBIN2005). 0 índice de conceptualização metafórica é definido como o elemento linguístico que evoca duas representações: uma factiva (mais verdadeira) e outra fictícia (menos verdadeira). Essas representações foram propostas inicialmente por Talmy (2001), sendo esse modelo de análise explorado em Medicina (VAndaele 2002a), Biologia Celular (VAndaele, Boudreau et al. 2006), Anatomia (LUBin 2006; Labelle 2009; VANDAeLE \& Lubin 2009) e, mais recentemente, na história da noção de gene (VANDAELE 2012).

Seguindo essa orientação, Lubin (2006; ver também VANDAELE \& LUBIN 2009) passou então a estudar os modos de conceptualização e as representações fictícias em Anatomia nas línguas francesa e inglesa, partindo de dois corpora comparáveis, formados por textos de anatomia descritiva.

Esses trabalhos, que propiciaram um vínculo sólido entre os estudos da metáfora e da tradução, a partir da noção de índice de conceitualização metafórica, deram origem a esta nova proposta, ou seja, avaliar se esses mesmos fenômenos ocorrem em língua portuguesa. Deste modo, a pesquisa que desenvolvemos buscou identificar e descrever, em língua portuguesa, os índices de conceptualização metafórica utilizados em Anatomia na descrição dos vasos sanguíneos e dos nervos e categorizá-los, com o objetivo de buscar padrões ou especificidades relacionadas a cada tipo de vaso sanguíneo e nervo.

Esta pesquisa se fundamenta em uma visão funcionalista da tradução (NORD 2008; REISS 2009), na medida em que a determinação e a utilização adequada dos índices e modos de conceptualização de uma área interferem 
MALASZKIEWICZ, P. F.; VANDAeLE, S.; ReUILLARD, P. C. R.- Conceptualização metafórica da anatomia em português: artérias, veias e nervos

diretamente em sua fraseologia e, consequentemente, em sua tradução para outra língua/cultura.

O objetivo deste artigo é, então, apresentar os primeiros resultados desta pesquisa ${ }^{2}$, cuja continuidade prevê o levantamento dos índices e modos de conceptualização dos músculos e a comparação entre os IC em língua portuguesa e língua francesa.

\section{Metodologia}

A busca dos índices e modos de conceptualização se dividiu em três etapas - constituição e preparação do corpus, identificação e classificação dos índices de conceptualização e definição dos modos de conceptualização metafórica -, que apresentamos a seguir.

\section{Etapa 1: Constituição e preparação do corpus}

Construímos um corpus com cerca de 50.000 palavras, formado por textos especializados da área de Anatomia, em língua portuguesa, e composto por obras de referência, ou seja, textos semelhantes ao corpus de referência em língua francesa utilizado no trabalho de Lubin (2006), que serviu de norte para nossa pesquisa. Todas as obras contêm textos de Anatomia Topográfica ou Descritiva porque neles encontram-se descrições relativas aos vasos sanguíneos e nervos e seu posicionamento no corpo humano. A princípio, pretendíamos incluir também textos traduzidos da língua francesa para a

\footnotetext{
${ }^{2}$ Este artigo é uma síntese da dissertação de mestrado Conceptualização Metafórica da Anatomia em português: artérias, veias e nervos, defendida pela autora em maio de 2013 na Universidade Federal do Rio Grande do Sul (UFRGS) e orientada pelas duas coautoras.
} 
MALASZKIEWICZ, P. F.; VANDAele, S.; ReuILlaRD, P. C. R.- Conceptualização metafórica da anatomia em português: artérias, veias e nervos

portuguesa a fim de verificar se as traduções seguiam os índices de conceptualização usuais em português ou mantinham os ICs do francês; no entanto, a maior parte das obras de referência em Anatomia publicada no Brasil é originalmente escrita em alemão ou inglês ${ }^{3}$. Por essa razão, textos traduzidos dessas línguas também foram acrescentados ao nosso corpus, por se tratarem de obras traduzidas e revisadas por especialistas brasileiros e largamente utilizadas para o aprendizado e a prática da Anatomia no Brasil. 0 período de publicação vai de 1965 a 2008; apesar de ter havido mudanças na terminologia médica nesse intervalo de tempo, isso não foi levado em consideração neste trabalho, pois não são os termos que estão em questão. Os textos, que estavam em formato impresso, foram digitalizados com o auxílio do software $A B B Y Y$ FineReader 11 e convertidos para o formato .txt., de modo a serem lidos por ferramentas de busca no corpus, por exemplo, do software AntConc (ANTHONY 2008).

\section{Etapa 2: Identificação dos índices de}

\section{conceptualização}

Após a digitalização e conversão, os contextos do corpus foram dispostos em tabelas do software Microsoft Excel contendo as seguintes colunas: contexto e fonte; índice de conceptualização metafórica (IC); actantes, (que são os agentes da ação indicada pelo índice de conceptualização, o verbo) e respectivas categorias; representação fictícia, domínio-fonte projetado e um espaço para comentários.

\footnotetext{
${ }^{3}$ Cf., por exemplo, GRAY's. Anatomia para estudantes, Elsevier, $2^{\mathrm{a}}$ ed. 2010 e NeTterAtlas de Anatomia Humana, Elsevier, $4^{\mathrm{a}}$ ed. 2008, ambos traduzidos do inglês; e SOBOTTA, J.; BECHER, H. Atlas de Anatomia Humana. 22. ed. Rio de Janeiro: Guanabara Koogan, 2006, traduzido do alemão.
} 
MALASZKIEWICZ, P. F.; VANDAele, S.; ReUILlARD, P. C. R.- Conceptualização metafórica da anatomia em português: artérias, veias e nervos

Por uma questão de espaço e para melhor visualização, adaptamos a tabela para este artigo.

Contexto: A artéria axilar, ultrapassando a borda inferior do músculo peitoral maior, passa a denominar-se artéria braquial (artéria umeral) que, percorre medialmente o braço, originando neste trajeto seu ramo mais calibroso, a artéria profunda do braço (artéria umeral profunda) (SILVA 1977: 26).

\begin{tabular}{|c|c|c|c|c|c|c|c|}
\hline IC & $\begin{array}{c}1^{\circ} \\
\text { actante }\end{array}$ & Categoria & $\begin{array}{c}2^{\circ} \\
\text { actante }\end{array}$ & Categoria & $\begin{array}{l}\text { Repres. } \\
\text { fictícia }\end{array}$ & $\begin{array}{l}\text { Domínio- } \\
\text { fonte } \\
\text { projetado }\end{array}$ & $\begin{array}{l}\text { Comentá } \\
\text { rios }\end{array}$ \\
\hline Ultrapassar & a. axilar & $\begin{array}{l}\text { vaso } \\
\text { sanguíneo/ } \\
\text { a. }\end{array}$ & $\begin{array}{l}\text { borda } \\
\text { inferior } \\
\text { do m. } \\
\text { peitoral } \\
\text { maior }\end{array}$ & $\begin{array}{l}\text { estruturas } \\
\text { anatômicas }\end{array}$ & deslocamento & $\begin{array}{l}\text { entidade em } \\
\text { deslocamento }\end{array}$ & \\
\hline Percorrer & $\begin{array}{l}\text { a. } \\
\text { braquial }\end{array}$ & $\begin{array}{l}\text { vaso } \\
\text { sanguíneo/ } \\
\text { a. }\end{array}$ & braço & $\begin{array}{l}\text { membro } \\
\text { superior / } \\
\text { braço }\end{array}$ & deslocamento & $\begin{array}{l}\text { entidade em } \\
\text { deslocament/ } \\
\text { curso d'água/ } \\
\text { caminho }\end{array}$ & \\
\hline Originar & $\begin{array}{l}\text { a. } \\
\text { braquial }\end{array}$ & $\begin{array}{l}\text { vaso } \\
\text { sanguíneo/ } \\
\text { a. }\end{array}$ & $\begin{array}{l}\text { artéria } \\
\text { profunda } \\
\text { do braço }\end{array}$ & $\begin{array}{l}\text { vaso } \\
\text { sanguíneo/ } \\
\text { art. }\end{array}$ & ação & $\begin{array}{l}\text { entidade que } \\
\text { provoca a } \\
\text { existência de } \\
\text { outra }\end{array}$ & \\
\hline
\end{tabular}

Quadro 1: Exemplo de tabela contendo a identificação dos índices de conceptualização encontradas no corpus.

0 índice de conceptualização metafórica é o elemento lexical que gera uma impressão de dissonância cognitiva entre as representações factiva e fictícia (VANDAele \& LubIN 2005). No exemplo acima, os índices de conceptualização são os verbos ultrapassar e percorrer. Percebe-se neles uma dissonância cognitiva entre a representação factiva, na qual os verbos denotam um deslocamento real (como na frase "o carro ultrapassou $O$ caminhão e percorreu todo o caminho em menos de duas horas"), e a representação fictícia ("a artéria ultrapassa o músculo"; "a artéria percorre o 
MALASZKIEWICZ, P. F.; VANDAele, S.; ReUILlaRD, P. C. R.- Conceptualização metafórica da anatomia em português: artérias, veias e nervos

braço"), na qual o deslocamento não existe, visto que, na realidade, a artéria permanece estática. A partir dessa dissonância, são estabelecidos os índices de conceptualização.

\section{Etapa 3: Classificação dos índices e definição dos modos de conceptualização metafórica}

A terceira etapa se consagrou a estabelecer, a partir de análises sucessivas, a que modo de conceptualização esses índices levam, buscando-se a compreensão da conceptualização metafórica presente e estabelecendo-se uma categorização. Essas categorias foram definidas anteriormente no trabalho de Lubin (2006), que partiu das categorias apresentadas por Talmy (2001). Para sua correta identificação, sublinhamos os índices de conceptualização e colocamos em itálico os actantes sobre os quais a conceptualização é projetada.

\section{Análise e resultados}

A partir da análise dos contextos dos índices de conceptualização elencados no corpus - 159 índices de conceptualização diferentes em um total de 1.985 ocorrências -, encontramos algumas categorias, que apresentamos a seguir.

a) Deslocamento fictício: o índice de conceptualização que apresenta essa representação fictícia denota uma entidade móvel que, na realidade, permanece estática. 
Malaszkiewicz, P. F.; VANDAele, S.; ReUillaRd, P. C. R.- Conceptualização metafórica da anatomia em português: artérias, veias e nervos

[A artéria ulnar] [p]assa lateralmente ao osso pisiforme e chega à região palmar.(SILVA 1977: 27)

A veia basílica, subindo pelo contorno medial do braço, aprofundase na sua porção média para desembocar logo acima nas veias braquiais. (FARIA 2003: 82)

Ele [nervo occipital] acompanhaa artéria vertebral e seus ramos inervam os músculos retos posteriores e oblíquos superior e inferior da cabeça. (DIDıo 2002: 827)

b) Ação fictícia: uma entidade inanimada é conceptualizada como uma entidade que executa uma ação, com um papel de agente.

A maioria dos ramos colaterais que dela [artéria braquial] parte vai irrigar preferencialmente os elementos da região anterior do braço, desde o úmero até a pele, enquanto para a região posterior do braço ela emite um ramo colateral importante que é a artéria profunda do braço (colateral externa ou umeral profunda) [...]. (CASTRO 2005: 238)

No lado medial da citada rede origina-se a veia basílica, que [...] perfura a fáscia aprofundando-se para se unir com as veias braquiais, na altura da borda inferior do músculo redondo maior [...]. (SILVA 1977: 27)

Nas proximidades do osso hioídeo o nervo laríngico superior dividese em dois ramos: um, o nervo laríngico interno, que, perfura a membrana tireo-hioldea para inervar a mucosa superior da laringe, e outro, situado inferiormente, o nervo laríngico externo, que inerva o músculo cricotireoídeo e distribui-se também na mucosa subglótica da laringe. (SILVA 1977:68)

c) Posicionamento fictício: o índice de conceptualização com essa representação denota a posição assumida pelo vaso sanguíneo ou nervo, a delimitação do lugar que ele ocupa no espaço. 
MALASZKIEWICZ, P. F.; VANDAele, S.; ReuILlaRD, P. C. R.- Conceptualização metafórica da anatomia em português: artérias, veias e nervos

As artérias circunflexas anterior e posterior do úmero dispõem-se ao redor do cólon cirúrgico do úmero e sua anastomose forma um anel. (DIDIO 2002: 386)

Superficialmente, a veia cefálica, proveniente do antebraço, ascende lateralmente na fossa cubital, posicionando-se no contorno lateral do bíceps braquial, cruzando proximalmente no sentido medial para colocar-se no sulco delto-peitoral e penetrar na axila pelo trígono delto-peitoral. (FARIA 2003: 82)

d) Surgimento fictício: nesta categoria de representação fictícia, o índice de conceptualização indica o surgimento de uma entidade inanimada que, na realidade, está sempre presente.

[A artéria auricular posterior] [t]ambém se dirige para cima e para trás, superficializando-se ao cruzar a borda do músculo estemoclidomastoídeo para se colocar logo atrás do pavilhão da orelha [...]. (CASTRO 2005: 229)

O n. acessórioemerge do esternocleidomastoideo no ponto em que o n. occipital menor aparece na borda posterior do músculo [...]. (CUNNINGHAM 1976: 19-20)

Aqui observamos uma primeira especificidade das artérias, visto que nenhuma ocorrência de índices de surgimento fictício foi encontrada na descrição das veias.

e) Orientação origem-fim: os índices de conceptualização desta categoria denotam a descrição do suposto nascimento de um vaso sanguíneo ou nervo e/ou até seu suposto fim.

A artéria subclávia direita, ramo de bifurcação do tronco braquiocefálico, situado atrás do músculo escaleno anterior, termina ao nível da margem lateral da I costela direita, onde se continua como artéria axilar. (DIDIO 2002: 385) 
MALASZKIEWICZ, P. F.; VANDAELE, S.; ReUILLARD, P. C. R.- Conceptualização metafórica da anatomia em português: artérias, veias e nervos

A v. cefálica nasce no lado radial do arco venoso dorsal [...]. (DANGELO \& FATTINI 2000: 350)

[O nervo mediano] [é] misto, nasce dos fascículos lateral e medial do plexo braquial na cavidade da axila por duas raízes que se unem em $\mathrm{V}$ [....]. Passa no canal do carpo, na palma termina bifurcando-se em ramos lateral e medial. (DIDIO 2002: 837)

É importante observar aqui que originar-se é classificado como orientação origem-fim, enquanto originar está classificado como ação fictícia porque este tem, em nossa opinião, um papel de agente.

Retomando o exemplo citado anteriormente:

A artéria axilar, ultrapassando a borda inferior do músculo peitoral maior, passa a denominar-se artéria braquial (artéria umeral), que percorre medialmente o braço [...]

Vê-se que a representação fictícia dos verbos ultrapassar e percorrer encaixa-se na categoria deslocamento fictício e conduz à conceptualização de uma entidade imóvel em entidade móvel. A partir disso, seria possível dizer, então, que AS ARTÉRIAS SÃO ENTIDADES MÓVEIS. No entanto, não se pode afirmar, sobre a base desse único exemplo, que essa seja uma conceptualização dominante. Só é possível chegar aos modos de conceptualização metafórica que retratam uma determinada área ou parte dela a partir da análise exaustiva e circular da totalidade dos dados coletados. Com essa metodologia obtivemos uma lista dos índices de conceptualização metafórica em língua portuguesa utilizados na Anatomia para a descrição do posicionamento das artérias, veias e nervos, e dos modos de conceptualização por eles expressos.

Apresentamos abaixo dois gráficos que exibem a distribuição do número de índices diferentes por categorização e também a quantidade de ocorrências de cada categorização em nosso corpus. Os 159 índices de conceptualização metafórica encontrados estão assim divididos: 
MALASZKIEWICZ, P. F.; VANDAele, S.; ReuILlaRD, P. C. R.- Conceptualização metafórica da anatomia em português: artérias, veias e nervos

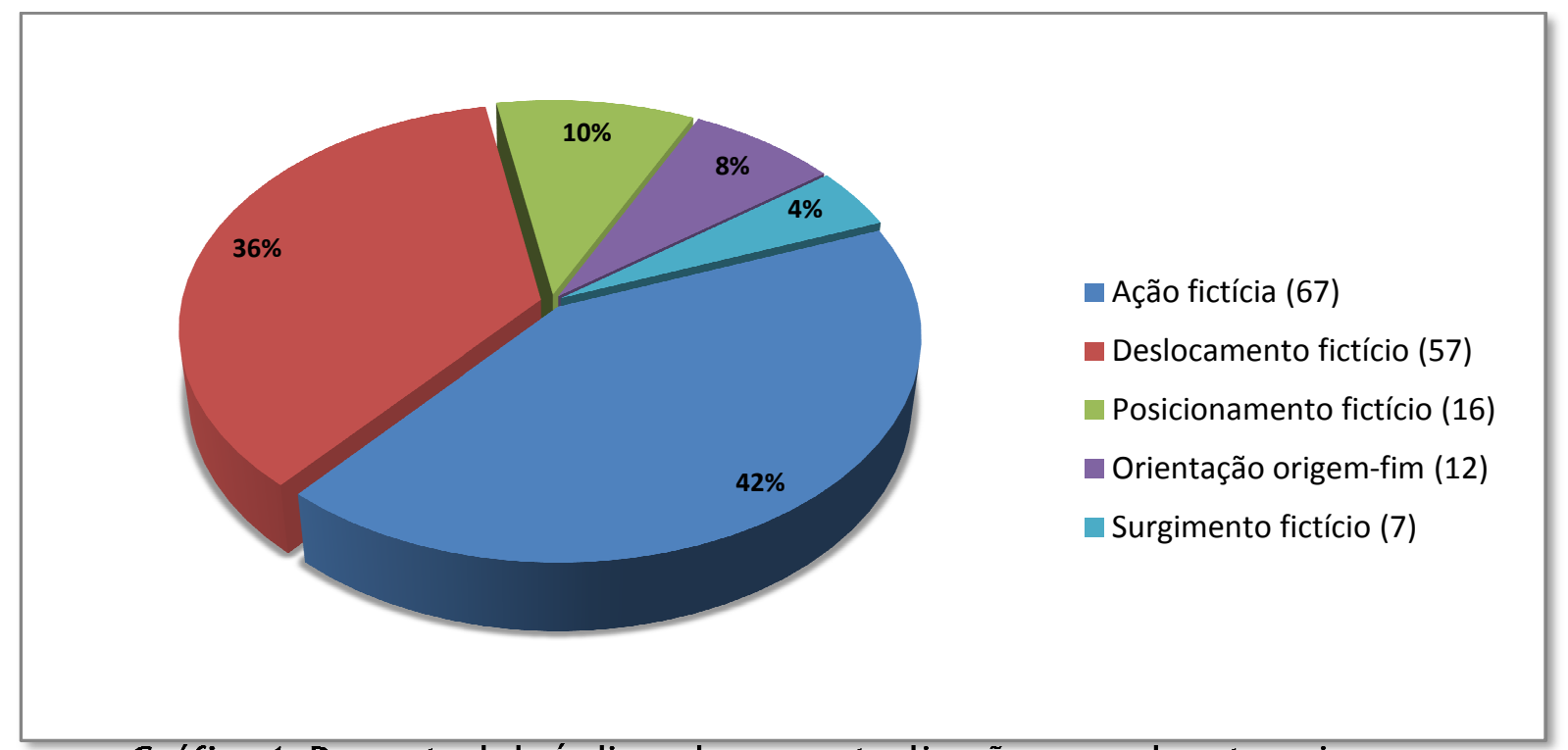

Gráfico 1. Percentual de índices de conceptualização em cada categoria.

No gráfico 1, podemos observar que há uma predominância dos índices de conceptualização indicando ação (42\%) ou movimento (36\%) fictício, somando $78 \%$ do total dos índices coletados. Os outros $22 \%$ se dividem entre as representações fictícias de posicionamento, surgimento e orientação origemfim.

No gráfico 2, expomos as ocorrências de índices de conceptualização metafórica por categoria. As 1.985 ocorrências encontradas no corpus foram assim distribuídas: 
MALASZKIEWICZ, P. F.; VANDAele, S.; ReUILlARD, P. C. R.- Conceptualização metafórica da anatomia em português: artérias, veias e nervos

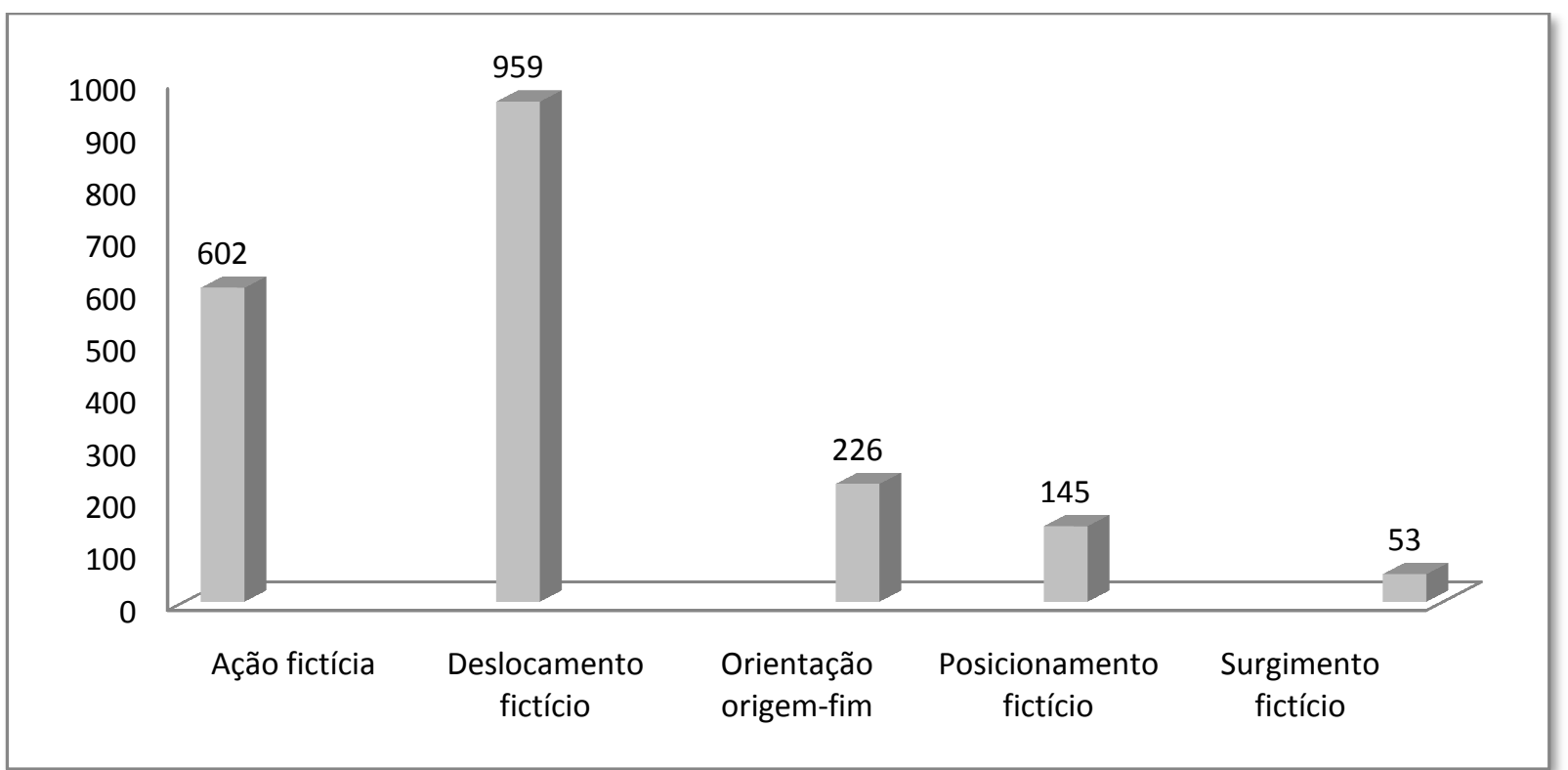

Gráfico 2. Quantidade de ocorrências de índices de conceptualização metafórica por categoria.

Comparando os gráficos 1 e 2, podemos observar que, embora haja uma ligeira predominância da quantidade de índices de conceptualização metafórica de ação fictícia em relação à quantidade de índices de conceptualização diferentes (57, contra 47 de deslocamento), no quesito quantidade de ocorrências há uma grande diferença entre as ocorrências de índices de deslocamento em relação aos índices de ação. Essas duas categorias, juntas, somam 1.561 das 1.985 ocorrências.

Após o levantamento, classificação e agrupamento dos índices, foram levantados os seguintes modos de conceptualização metafórica:

\begin{tabular}{|l|c|c|c|c|c|}
\hline & $\begin{array}{c}\text { ENTIDADES } \\
\text { MÓVEIS }\end{array}$ & CAMINHOS & $\begin{array}{c}\text { CURSOS } \\
\text { D'ÁGUA }\end{array}$ & $\begin{array}{c}\text { ENTIDADES } \\
\text { ANIMADAS }\end{array}$ & FERRAMENTAS \\
\hline ARTÉRIAS SÃO... & $\mathrm{X}$ & $\mathrm{X}$ & $\mathrm{X}$ & $\mathrm{X}$ & $\mathrm{X}$ \\
\hline VEIAS SÃO.. & $\mathrm{X}$ & $\mathrm{X}$ & $\mathrm{X}$ & $\mathrm{X}$ & $\mathrm{X}$ \\
\hline NERVOS SÃO... & $\mathrm{X}$ & $\mathrm{X}$ & & $\mathrm{X}$ & $\mathrm{X}$ \\
\hline
\end{tabular}

Quadro 2: Índices de conceptualização metafórica levantados pela pesquisa. 
MALASZKIEWICZ, P. F.; VANDAele, S.; ReuILlaRD, P. C. R.- Conceptualização metafórica da anatomia em português: artérias, veias e nervos

Podemos observar que as estruturas - artérias, veias e nervos - são conceptualizadas de modo semelhante, à exceção dos nervos, que não são conceptualizados como cursos d'água. Além disso, o fato de as conceptualizações serem as mesmas não significa que os índices também o sejam.

Ilustramos, primeiramente, o modo de conceptualização das artérias e veias como cursos d'água com os seguintes exemplos de descrições de cursos d'água, seguidos por trechos de descrições dos vasos retirados do nosso corpus:

Seu rio principal [da Bacia Hidrográfica Amazônica] (Amazonas), nasce no Peru com o nome de Vilcanota e recebe posteriormente os nomes de Ucaiali, Urubamba e Marañon. Quando entra no Brasil, passa-se a chamar Solimões e, após o encontro com o Rio Negro, perto de Manaus, recebe o nome de Rio Amazonas. O Rio Amazonas percorre $6.280 \mathrm{~km}$, sendo o segundo maior do planeta em extensão (após o Rio Nilo, no Egito, com $6.670 \mathrm{~km}$ ) é o maior do mundo em vazão de água. ${ }^{4}$

Após percorrer 200 quilômetros através de um estreito vale em meio ao Himalaia, o Ganges passa por um desfiladeiro e chega na planície Gangética, na cidade de Haridwar, centro de peregrinação; lá, uma represa desvia parte de suas águas até o Canal do Ganges, que irriga a região de Doab, em Uttar Pradesh. ${ }^{5}$

O rio Paraguai nasce na Chapada dos Parecis, no Mato Grosso. Ao longo do seu percurso rumo ao sul, recebe vários afluentes importantes como o Cuiabá, o São Lourenço, o Taquari, o Miranda e o Negro. ${ }^{6}$

4 PORTAL SÃo Francisco. Bacias Hidrográficas $e$ rios. Disponível em: www.portalsaofrancisco.com.br/alfa/rios-brasileiros/rios-brasileiros-5.php. Acesso em: 6 mar. 2013.

${ }^{5}$ WIKIPEDIA. Rio Ganges. Disponível em: http://pt.wikipedia.org/wiki/Rio_Ganges. Acesso em: 6 mar. 2013.

6 BRASIL. Rios e Bacias. Disponível em: www.brasil.gov.br/sobre/meioambiente/geografia/rios-e-bacias. Acesso em: 7 mar. 2013. 
MALASZKIEWICZ, P. F.; VANDAele, S.; ReUILlaRD, P. C. R.- Conceptualização metafórica da anatomia em português: artérias, veias e nervos

Com 2.200 km de extensão, o rio Uruguai nasce na junção dos rios Pelotas e Peixe, e segue em direção ao oeste dividindo os Estados do Rio Grande do Sul e Santa Catarina. Em seu caminho, ele também se une com o rio Peperi-Guaçu, servindo de fronteira entre Brasil e Argentina. Seguindo na direção sudoeste, o Uruguai se une com o rio Quarai (que limita o Brasil e o Uruguai) e daí toma a direção sul, passando a dividir Argentina e Uruguai até a sua foz. ${ }^{7}$

\section{A lagoa desemboca no rio Mampituba, que tem ligação com o mar. ${ }^{8}$}

Apresentamos a seguir, para comparação, alguns exemplos do corpus:

A artéria femoral, vaso de grande calibre, é a principal artéria do membro inferior. Teminício no ânulo femoral, como continuação da ilíaca externa. Segue no trígono femoral e após se introduz no canal adutor (canal de Hunter) percorrendo-o em toda sua extensão. Deixa o referido canal através do anel do músculo adutor magno, e daí em diante, com a denominação de artéria poplítea, atravessa profundamente a região de igual nome. (SILVA 1977: 230)

A veia femoral profunda recebe como afluentes as veias correspondentes aos ramos perfurantes da artéria femoral profunda e, por meio deles, se anastomosa com as veias poplítea e glútea inferior, e recebe também as veias circunflexas laterais e mediais do fêmur. (DIDIO 2002: 413)

[veia jugular externa] Com trajeto descendente, cruza o esternocleidomastóideo, obliquamente, coberta pelo platisma. Desemboca na $v$. subclávia ou, às vezes, na v. jugular interna. (DANGELO\&FATTINI 2000: 439)

Veia tireóidea superior: nasce do parênquima e da superfície do quadrante superolateral da glândula tireóidea, recebe as veias

7 BRASIL. Rios e Bacias. Disponível em: www.brasil.gov.br/sobre/meioambiente/geografia/rios-e-bacias/print. Acesso em: 7 mar. 2013.

8 WIKIPEDIA. Lagoa de Sombrio. Disponível em: http://pt.wikipedia.org/wiki/Lagoa_de_Sombrio. Acesso em: 8 mar. 2013. 
MALASZKIEWICZ, P. F.; VANDAele, S.; ReuILlaRD, P. C. R.- Conceptualização metafórica da anatomia em português: artérias, veias e nervos

laríngea superior e cricotireóidea. Desemboca na parte superior da jugular interna. (DIDIO2002: 405)

Comparando as descrições dos cursos d'água e do posicionamento das artérias no corpo humano, observamos que são muito semelhantes, o que confirma nossa afirmação de que as artérias e veias são conceptualizadas parcialmente como cursos d'água. Além disso, pudemos observar algumas construções específicas das veias, tais como:
a) veia $x$ se une à veia $y$
b) veia $x$ recebe veia $y /$ afluente
c) veia $x$ desemboca em veia $y$

que correspondem exatamente à construção da descrição dos cursos d'água:
d) curso d'água xse une ao curso d'água y
e) curso d'água xrecebecurso d'água y / afluente
f) curso d'água xdesemboca em curso d'água y

Aqui vemos claramente que as veias estão conceptualizadas como cursos d'água, pois desempenham o mesmo papel, ou seja, o conceito de curso d'água (expresso no discurso por Rio Amazonas, Rio Uruguai, etc.) se projeta sobre o de vasos sanguíneos (expressos no discurso pelo nome de diversos vasos sanguíneos, tais como artéria femoral, veia subclávia e outros). Esses exemplos ressaltam, também, o quanto os índices de conceptualização interferem na fraseologia de uma área do conhecimento, pois formas como artéria $x$ desemboca na veia $x$ / artéria $x$ não seriam aceitas em língua portuguesa.

Vandaele (2010) já havia observado que desembocar ocorria em língua portuguesa, assim como em língua espanhola (desembocar en), para descrever a união de dois vasos sanguíneos (pp. 296). A autora constatou também que o equivalente em francês para desembocar, o verbo se jeter, evocava ao mesmo 
MALASZKIEWICZ, P. F.; VANDAELE, S.; ReUILLARD, P. C. R.- Conceptualização metafórica da anatomia em português: artérias, veias e nervos

tempo a união de dois cursos d'água (la Saône se jette dans le Rhône) e o deslocamento fictício de uma entidade que salta de um lugar para o outro (Jean se jette dans la rivière [Jean se joga no rio]), o que não ocorre em português e em espanhol, ocorrendo em ambas as línguas apenas a representação fictícia da união de dois cursos d'água.

Voltamos a lembrar que o fato de duas estruturas diferentes compartilharem o mesmo modo de conceptualização não significa que tenham os mesmos índices de conceptualização metafórica. Por exemplo, o índice irrigar é encontrado somente na descrição das artérias, enquanto o índice drenar é encontrado apenas na descrição das veias, como podemos ver nos exemplos abaixo:

As artérias carótidas comuns irrigam a cabeça e o pescoço e se bifurcam em artérias carótidas externa e interna. (DIDIo 2002: 382)

[A v. jugular externa] [d]rena a maior parte da face e do couro cabeludo, além de conter uma quantidade significante de sangue cerebral. (DANGELO \& FATTINI 2000: 439)

Podemos atribuir o uso específico dos índices irrigar e drenar à função das artérias e veias. Enquanto as artérias têm a função de distribuir o sangue do coração para o corpo, ou seja, de irrigar o corpo, as veias têm a função de levar o sangue de volta para o coração, ou seja, drenar. Esses achados corroboram, em língua portuguesa, os resultados de Lubin (2006) e Vandaele \& Lubin (2009) em língua francesa, que mostraram que irriguer e drainer são índices utilizados especificamente na descrição das artérias e das veias, respectivamente, e evocam a conceptualização dessas estruturas como cursos d'água.

Finalmente, relembramos que a conceptualização metafórica de curso d'água não se aplica aos nervos. No entanto, as três estruturas - artérias, veias e nervos - compartilham a conceptualização de um caminho, conforme 
MALASZKIEWICZ, P. F.; VANDAele, S.; ReuILlaRD, P. C. R.- Conceptualização metafórica da anatomia em português: artérias, veias e nervos

podemos observar nos exemplos seguintes, que descrevem caminhos e, em seguida, em exemplos extraídos do corpus de trabalho:

Também conhecida como Highway 93 Alberta do Norte, a estrada atravessa a paisagem acidentada das Montanhas Rochosas canadenses. ${ }^{9}$

Partindo do centro de Corupá a $80 \mathrm{~m}$ de altitude [...] exatamente no acesso ao seu cume a estrada contorna o referido morro. ${ }^{10}$

As cidades antigas eram cêntricas [...]. Todas as estradas confluem para a cidade, seguem em direção ao centro. ${ }^{11}$

N. obturatório (n. obturador): alcança o buraco obturatório, o qual atravessa juntamente com os vasos obturatórios[...]. (ALVES 1965: 490)

[...] enquanto que a $a$. circunflexa anterior contorna de diante para trás o colo cirúrgico daquele osso [úmero] [...]. (ALVES 1965: 464465)

Veia basílica: [...] sobe no antebraço, segue ao longo da margem medial do bíceps e conflui com as braquiais para constituir a veia axilar. (DıDıo 2002: 407)

Esse fenômeno também foi observado anteriormente em língua francesa por Vandaele, Boudreaud et al (2006: 86).

9 VIAGENS IG. As mais incríveis estradas do mundo. Disponível em: www.viagens.ig.com.br/destinos/as-mais-incriveis-estradas-do-mundo. Acesso em: 30 abr. 2013.

${ }^{10}$ VILA ECOLÓGICA. Sumário. Disponível em: www.vilaecologica.com.br/pt/?area=sumario\&tid=11. Acesso em: 30 abr 2013.

${ }^{11}$ Governo Do Estado De São PaUlo. Com obra, caminhos não levarão ao centro. Disponível em: www.saopaulo.sp.gov.br/spnoticias/lenoticia.php?id=207055\&c=201. Acesso em: 30 abr. 2013. 
MALASZKIEWICZ, P. F.; VANDAeLE, S.; ReUILLARD, P. C. R.- Conceptualização metafórica da anatomia em português: artérias, veias e nervos

\section{Considerações finais}

O estudo dos índices e modos de conceptualização metafórica é fundamental para compreender a fraseologia de uma área de conhecimento. De fato, o conhecimento desses índices e modos está diretamente ligado à idiomaticidade de uma área específica e é decisivo no momento de uma tradução, visto que seu uso incorreto pode causar estranheza ou incompreensão para o leitor, comprometendo a qualidade do texto traduzido.

Concordamos com Vandaele (2010) que, embora os termos ainda ocupem uma preocupação central na tradução de textos especializados, a tradução da fraseologia pode se mostrar muito mais problemática, já que ela vai além da simples busca de equivalentes. Estando a fraseologia de uma área especializada diretamente ligada aos índices de conceptualização metafórica, o uso correto desses índices em uma tradução torna o texto mais idiomático e, portanto, aceito na língua de chegada.

Por fim, destacamos a relevância desse tipo de pesquisa não somente na área da Anatomia, pois se sabe que os índices e modos de conceptualização metafórica estão presentes em todas as áreas do conhecimento humano. Dominar os índices de conceptualização é, portanto uma ferramenta fundamental para o tradutor de textos especializados.

\section{Referências bibliográficas}

Beardsley, M., Aesthetics, New York: Brace \& World, 1958.

BLACK, M. Models and metaphors, New York: Cornell University Press, 1962.

FABER, Pamela. A Cognitive Linguistics View of Terminology and Specialized Language. Berlim: Mouton de Gruyter, 2012. 
MALASZKIEWICZ, P. F.; VANDAele, S.; ReUILlaRD, P. C. R.- Conceptualização metafórica da anatomia em português: artérias, veias e nervos

HUANG, C. A metáfora no texto científico de medicina: um estudo terminológico da linguagem sobre AIDS. Dissertação de Mestrado, UFRGS, 2005.

LABELLE, M. Les réseaux lexicaux nominaux témoignant de la conceptualisation métaphorique en anatomie, mémoire de maîtrise, Université de Montréal, 2009. Sob orientação da Prof. Sylvie Vandaele.

Lakoff, G.; Johnson, M. Metaphors We Live by - With a New Afterwords. Chicago: The University of Chicago Press, 1980. Metáforas da Vida Cotidiana. São Paulo: Mercado das Letras, 2002.

LUBIN, L. Étude des métaphores conceptuelles utilisées dans la description des structures anatomiques, mémoire de maîtrise, Université de Montréal, 2006. Sob orientação da Prof. Sylvie Vandaele.

MEL'C`UK, I. A.; CLAS, A.; POLGUÈRE, A.. Introduction à la lexicologie explicative et combinatoire, Louvain-la-Neuve (Belgique), Duculot / Aupelf UREF, 1995.

NoRD, C. La traduction, une activité ciblée: introduction aux approches fonctionnalistes. Traduzido do inglês por Beverly Adab. Arras: Artois Presses Université, 2008.

OliveIRA, L. P. 2011. 274f. Tese (Doutorado). Aspectos linguísticos, comunicativos e cognitivos das metáforas terminológicas: uma análise baseada em um corpus da Genética Molecular.

REDDY, M. J. The conduit metaphor - a case of frame conflict in our language about language. In: ORTONY, A. (Org.). Metaphor and thought. Nova York, Cambridge University Press, 1979.

REISS, K. Problématiques de la traduction. Traduzido do alemão por Catherine A. Bocquet. Paris: Ed. Economica, 2009.

RICHARDS, I. A. The Philosophy of Rhetoric. New York: Oxford UP, 1936.

Temmerman, R. Towards New Ways of Terminology Description: The Sociocognitive Approach, Amsterdam, John Benjamins, 2000.

VANDAELE, S. Métaphores conceptuelles et traduction biomédicale. In: La traduction : théorie et pratiques, actes du colloque international Traduction humaine, traduction automatique, interprétation, sous la dir. de S. Méjri, T. Baccouche, A. Clas, G. Gross, Tunis, 28-29 septembre 2000, Publications de l'ENS, pp. 393-404. 
MALASZKIEWICZ, P. F.; VANDAele, S.; ReUILlaRD, P. C. R.- Conceptualização metafórica da anatomia em português: artérias, veias e nervos

Métaphoresconceptuelles en traduction médicale et cohérence, TTR, XV(1): 223-239, 2002a.

. Publicités médico-pharmaceutiques et métaphores conceptuelles. Actes du colloque Training the Language Services Provider for the New Millennium,Proceedings of the III Encontros de Tradução de Astra-FLUPFaculdade de Letras, Universidade do Porto. Ss la direction de B. Maia, J. Haller et M. Ulyrch, 2002b, pp. 329-339.

- Deciphering metaphorical conceptualization in biomedicine: towards a systematic analysis, LSP 2003, Surrey, Angleterre, août 2003. ISBN: 1-84469007-5. New Directions in LSP Studies Proceedings of the 14th European Symposium on Language for Special Purposes, 18 - 22 August 2003, Communication, Culture, Knowledge, Margaret Rogers and Khurshid Ahmad (Editors), pp. 195-202, 2004.

- Conceptualisation métaphorique en biomédecine : importance pour le processus traductionnel. Congrès de l'ABECAN (Associação Brasileira de Estudos Canadenses), Novembre 2005, Gramado. In: HaNCIAU, N. (Org.). Brasil / Canadá: visões, paisagens e perspectivas, do Ártico ao Antártico. Rio Grande: Ed. da FURG, 2006. [sous presse] : 281 - 294.

- Quelques repères épistémologiques pour une approche cognitive de la traduction spécialisée - Application à la biomédecine. Meta, v. 52, n. 1, pp. 129-145, 2007.

. Os modos de conceitualização do ser vivo: uma abordagem linguística. Traduzido por Joice Monticelli Furtado e Paula Fernanda Malaszkiewicz, Cadernos de Tradução, n. 25, pp. 1-278, 2009.

- Términos y unidades léxicas en la traducción especializada: de la noción a los modos de conceptualización. In: IsQUeRDO, A. N.; BARROS, L. A. As Ciências do Léxico - lexicologia, lexicografia, terminologia, v. 5, Campo Grande, UFMS, pp. 279-298, 2010.

Vandaele, S.; Beland, M.-C. Les modes de conceptualisation des « unités d'hérédité 》 au XIXe siècle. In: Vicent Montalt et Mark Shuttleworth, Translation and Knowledge Mediation in Medical and Health Settings, Linguistica Antverpiensa, v. 11, pp. 227-246, 2012.

VANDAele, S.; Boudreau, S. Annotation XML et interrogation de corpus pour l'étude de la conceptualisation métaphorique. JADT 2006, Journées internationales d'analyses statistiques des données textuelles, Besançon, 1921 avril 2006. V. 2, pp. 951-959. 
MALASZKIEWICZ, P. F.; VANDAele, S.; ReuILlaRD, P. C. R.- Conceptualização metafórica da anatomia em português: artérias, veias e nervos

VANDAELE, S., BoudReau, S. et al. La conceptualisation métaphorique en biomédecine: indices de conceptualisation et réseaux lexicaux, Glottopol, v. 8, pp. 73-94, 2006.

VANDAELE S.; LUBIN, L. Approche cognitive de la traduction dans les langues de spécialité : vers une systématisation de la description de la conceptualisation métaphorique. Meta, 50(2): 415-431, 2005; Abordagem cognitiva da tradução nas línguas de especialidade: para uma sistematização da descrição da conceituação metafórica, traduzido por Daniel Costa da Silva, Cadernos de Tradução, n. 20, pp. 77-97, Instituto de Letras/UFRGS, Bevilacqua, C. e Reuillard, Patrícia (Orgs.), 2007.

VANDAELE, S.; LUBIN, L. Modes de conceptualisation et représentations fictives en anatomie. In: Dury, P. et al., dir. La métaphore en langues de spécialité, Grenoble, Presses Universitaires de Grenoble, pp. 61-81, 2009.

\section{Bibliografia do corpus}

Alves, E. Anatomia Descritiva. São Paulo: Atheneu, 1965.

CASTRO, S. B. Anatomia Fundamental. São Paulo: Pearson Makron Books, 2005.

CunNinghaM, D. Manual de anatomia pratica. v. 1 e 3. São Paulo, Atheneu, 1976.

Dangelo, J. G.; Fattinı, C. A. Anatomia Básica dos Sistemas Orgânicos. São Paulo: Atheneu, 2000.

DIDıo, L. J. A. Tratado de Anatomia Sistêmica Aplicada. Tomo 2. São Paulo: Atheneu, 2002.

FARINA JÚNIOR, R. Anatomia dos membros. Porto Alegre: EDIPUCRS, 2003.

Platzer, W. Anatomia - Texto e Atlas. v. 1. Porto Alegre: Artmed, 2008.

SILVA, C. A. Estudos de Anatomia do Corpo Humano. Porto Alegre: Instituto de Biociências da UFRGS, 1977. 